\title{
Innovations
}

\section{Islamic bioethical discourse in incidental findings: Research genetic context}

\author{
Medical Humanities in the Middle East Conference \\ November 17-18, 2018 \\ Doha, Qatar
}

\section{Authors}

\section{Alya Al Shakaki ${ }^{\star}$}

\section{Abstract}

In December 2013, a male Qatari patient with unknown liver disease was recruited from Hamad General Hospital - Doha to undergo a genetic research study initiated and managed by Weill Cornell Medicine-Qatar (WCM-Q). The purpose of the recruitment was to carry out further DNA genetic research testing to build a comprehensive catalogue of genetic variants in the Arab world that could eventually aid physicians to conclude a proper diagnosis of complex cases. The nature of the research study required the involvement not only of the patient but also the immediate family members, especially given that some of the patient's siblings shared the same disease.

Whole Exome Sequencing ${ }^{+}$(WES) test was conducted on the DNA samples taken from the family members including the patient. The test uncovered the mutant gene in the affected members that caused deterioration of the liver, which solved the mystery of the case. While the main objective of the research study was to look for the effective gene associated with the liver disease, another mutant gene showed up, incidentally, in the results that fell outside the main purpose of the test, which was a mutation in a gene that causes hearing loss and deafness. This incidental finding was discovered in two family members.

+ A laboratory process that is used to determine the nucleotide sequence primarily of the exonic (or protein-coding) regions of an individual's genome and related sequences, representing approximately $1 \%$ of the complete DNA sequence.

Weill Cornell Medicine - Qatar, Doha, Qatar

*Email: aaa2017@qatar-med.cornell.edu
Cite this article as:

Al Shakaki, A. Islamic bioethical discourse in incidental findings: Research genetic context. In: Weber AS, Verjee MA, editors. Proceedings of the 1st International Conference on Medical Humanities in the Middle East [Internet]; 2018 Nov 17-18: Doha, Qatar: Innovations in Global Health Professions Education; 2019 March. p. 22-23. (Innovations in Global Health Professions Education; vol. 2019, spec. no.: 1). https://dx.doi.org/10.20421/ ighpe2019.01.07

This is an open access article distributed under the terms of the Creative Commons Attribution license CC BY 4.0, which permits unrestricted use, distribution and reproduction in any medium, provided the original work is properly cited. 
This is an example of Incidental Findings (IFs) which are defined as the results that arise outside the original purpose for which the test or procedure was conducted.' This situation put the research team in a challenging ethical dilemma as it was the first time they encountered this issue. How should we, as a research team, deal with this case? Should the unexpected result be disclosed to the family in the first place? And if yes, who is responsible to disclose these findings to the family (the researcher, primary care provider, genetic counselor, etc.)? Are we obliged to report this to the two affected members only, so we don't breach confidentially, or to all the family members? This is because genetic information has implications not just for the tested individuals, but for biologically linked family members as well.

The ethical management of Incidental Findings in the context of genomics is a global, contemporary, rising and challenging topic that is certainly worthwhile of careful analysis and research. Furthermore, it is also needed to develop an Islamic discourse regarding this emerging topic that has not been directly discussed in the classical Islamic tradition. Nevertheless, the rich Islamic tradition provides a solid ground to build a more specific discourse on the particular topic of managing Incidental Findings. In particular, the engagement of al ahkam al khamsa (the five main ethico-legal categories: obligatory, recommended, permissible, reprehensible and prohibited) provides an elegant and comprehensive system to categorize all acts ethically. ${ }^{2}$ In addition to the higher objectives of Sharia and figh maxims, we should also consider the international agreements of bioethics, and reconcile them with the tradition of Islam, as appropriate, because such international agreements have their own weight and significance worldwide, and in most cases, they do not necessarily conflict with sharia objectives, but rather they align with them very well. In principle, the ethical judgment of any particular incidental findings case should be based on acquiring benefits and preventing harms, and judging the net effect when there are conflicting benefits and harms. In order to be able to have a careful judgment of the actual benefits and harms of disclosing any Incidental Finding to the participant, the following variables should be carefully assessed: analytical/clinical validity, clinical actionability, which is known as clinical utility, how serious the condition is, the participant desire, and the effect on the offspring. ' According to these criteria, we can add up our pluses and minuses to assess the net benefit or harm of revealing the IFs to the participant.

\section{Conflicts of interest: None.}

Funding sources: None.

\section{References}

1. Weiner C. Anticipate and communicate: Ethical management of incidental and secondary findings in the clinical, research, and direct-to-consumer contexts (December 2013 report of the Presidential Commission for the Study of Bioethical Issues). Am J Epidemiol. 2014 Sep 15 [cited 2019 Feb 19];180(6):562-4. Available from: https://academic.oup.com/aje/ article/180/6/562/2739282. doi:10.1093/aje/ kwu217

2. Faruki K. Al-ahkām al-khamsah: The five values. Islamic Studies. 1966 Mar;5(1):43-98.

\section{About the author}

Alya Al Shakaki is a Clinical Research Coordinator at Weill Cornell Medicine - Qatar, where she is involved in multiple research projects such as Genetics of Mendelian Diseases in Qatar and type 2 diabetes in Qataris. She received her B.Pharm from Ajman University of Science and Technology in UAE in 2006, and has pursued the field of Genetic research since 2010 at WCM-Q. She co-authored multiple papers published in renowned journals and conferences. Alya is currently doing a Master's Degree in Islamic Studies with a concentration in Islamic Thought and Applied Ethics at the College of Islamic Studies (CIS), HBKU. Her research interest is in the field of ethics and Islam in genomics. 